\title{
Pelatihan Perhitungan Arah Qiblat dan Awal Waktu Shalat Sesuai Standar Kementerian Agama Republik Indonesia di Kabupaten Batang Jawa Tengah
}

\author{
Ma'rifat Iman', Tricahyono1, Fira Mariza1 \\ ${ }^{1}$ Universitas Muhammadiyah Prof. DR. HAMKA Jl. Tanah Merdeka, Jakarta Timur, Indonesia \\ Email: marifat.iman@uhamka.ac.id
}

\begin{abstract}
Abstrak
Terbentuknya kader-kader Muhammadiyah yang memahami dan mahir perhitungan falakiyah, khususnya perhitungan waktu-waktu ibadah (arah qiblat dan waktu-waktu shalat). Sedangkan manfaat yang diperoleh dari pelatihan ini Terjalinnya kerjasama dengan para mitra kerja, yang dapat ditindaklanjuti dengan kegiatan lainnya di masa mendatang. Metode yang digunakan dalam kegiatan ini adalah memberikan motivasi, memberikan wawasan umum dan dasar-dasar ilmu falak tentang letak geografis suatu tempat di permukaan bumi, dan memberikan ilmu perhitungan arah qiblat dan waktu-waktu shalat, serta praktik pengukuran arah qiblat. Hasil atau luaran yang dihasilkan dari kegiatan ini Antara lain terdapat 70\% (35 orang dari 50 orang) peserta pelatihan mampu melakukan perhitungan arah qiblat dan mempraktikkan pengukurannya; sekurangkurangnya 60\% (30 orang dari 50 orang) peserta pelatihan mampu menghitung awal waktu shalat dengan mempraktikkan software winhisab yang menjadi standar Kementerian Agama Republik Indonesia.
\end{abstract}

Kata Kunci : Pelatihan, Kiblat, waktu sholat, Winhisab

\begin{abstract}
The formation of Muhammadiyah committee who understood and also adopted to the calculation of Falakiyah, especially the calculation of worship times (qibla direction and prayer times) became one of the reason why this community services need to be done. Meanwhile, the benefits of this activity were to perform the partnership between the associates to carry out the future plans. Giving motivation and also sharing general knowledge in training became the method of this community service. At the training, the participants were introduced to the basic knowledge about geographical location in astronomy, how to calculate the qibla direction and times of prayer,and practice of measuring qibla direction.the outcome of this activity was at least $70 \%$ (35 out of 50 participants) were able to calculate the start of prayer time by practicing the winhisab software that is the standard of the Ministry of Religious Affairs of the Republic of Indonesia.
\end{abstract}

Keywords; Training, Qibla, Times of Prayer, Winhisab

Format Sitasi: Iman, M.M., Tricahyono \& Fira Mariza. (2018). Pelatihan Perhitungan Arah Qiblat dan Awal Waktu Shalat Sesuai Standar. Jurnal SOLMA, 07(1), 33-41

Revisi: 23-01-2018; Diterima: 22-02-2018; Diterbitkan: 07-04-2018.

\section{PENDAHULUAN}

Arah Qiblat, dua kata ini yang akan dicari formulasi dan hitungan penentuannya. Kata arah berarti jurusan, tujuan dan maksud (Departemen P\&K, Kamus Besar Bahasa Indonesia, 1999), Imam Syafi'i berpendapat mencari arah qiblat dengan sungguh-sungguh dan arah yang terdekat. Demikian juga memberi arti menghadap jarak terdekat (Saadoe'ddin Djambek, Arah Qiblat, 1956) yang diukur melalui lingkaran besar pada permukaan bumi. Yang lain mengartikan dengan kata jihat, syathrah dan azimuth 
(Departemen Agama, Pedoman Penentuan Arah Qiblat, 1994). Sedangkan kata Qiblat berarti Ka'bah yang terletak di dalam Masjid al-Haram kota Mekah. Para ulama sepakat menghadap ke arah qiblat merupakan syarat sahnya shalat, maka kaum muslimin wajib menghadap ke arah qiblat dalam melakukan ibadah shalat. Dengan demikian arah qiblat adalah suatu arah (kiblat di Mekah) yang wajib dituju oleh umat Islam ketika ibadah shalat.

Arah kota Mekah yang terdapat Ka'bah (sebagai qiblat kaum muslimin) dapat diketahui dari setiap titik yang berada di permukaan bola bumi, maka untuk menentukan arah qiblat dapat dilakukan dengan menggunakan Ilmu Ukur Segitiga Bola (Spherical Trigonometri). Penghitungan dan pengukuran dilakukan dengan derajat sudut dari titik kutub utara, dengan menggunakan alat bantu mesin hitung atau kalkulator. Atau dapat ditentukan dengan cara mengetahui jam bayang-bayang qiblat setiap hari di permukaan bumi ini.

Untuk perhitungan arah qiblat, ada 3 buah titik yang harus dibuat, yaitu:

1. Titik A, diletakkan di Ka'bah (Mekah)

2. Titik B, dletakkan di lokasi tempat yang akan ditentukan arah qiblatnya.

3. Titik C, diletakkan di titik kutub utara.

Titik A dan titik $\mathrm{C}$ adalah dua titik yang tetap (tidak berubah-ubah), karena titik A tepat di Ka'bah (Mekah) dan titik C tepat di kutub utara (titik sumbu), sedangkan titik B senantiasa berubah, mungkin berada di sebelah utara equator dan mungkin pula berada di sebelah selatannya, tergantung pada tempat mana yang akan ditentukan arah qiblatnya.

Bila ketiga titik tersebut dihubungkan dengan garis lengkung pada lingkaran besar, maka terjadilah segitiga bola $\mathrm{ABC}$, seperti gambar di bawah ini. Titik A adalah posisi Ka'bah (Mekah), titik B adalah posisi lokasi tempat/kota, dan titik C adalah kutub utara/titik sumbu.

Gambar 1 menjelaskan bahwa yang dimaksud dengan perhitungan arah qiblat adalah suatu perhitungan untuk mengetahui berapa besar nilai sudut $\mathrm{B}$, yakni sudut yang diapit oleh sisi a dan sisi C.

Pembuatan gambar segitiga bola seperti di atas sangat berguna untuk membantu menentukan nilai sudut arah qiblat bagi suatu tempat di permukaan bumi ini dihitung/diukur dari suatu titik arah mata angin ke arah mata angin lainnya, misalnya diukur dari titik Utara ke Barat (U-B), atau diukur searah jarum jam dari titik Utara (UTSB). 


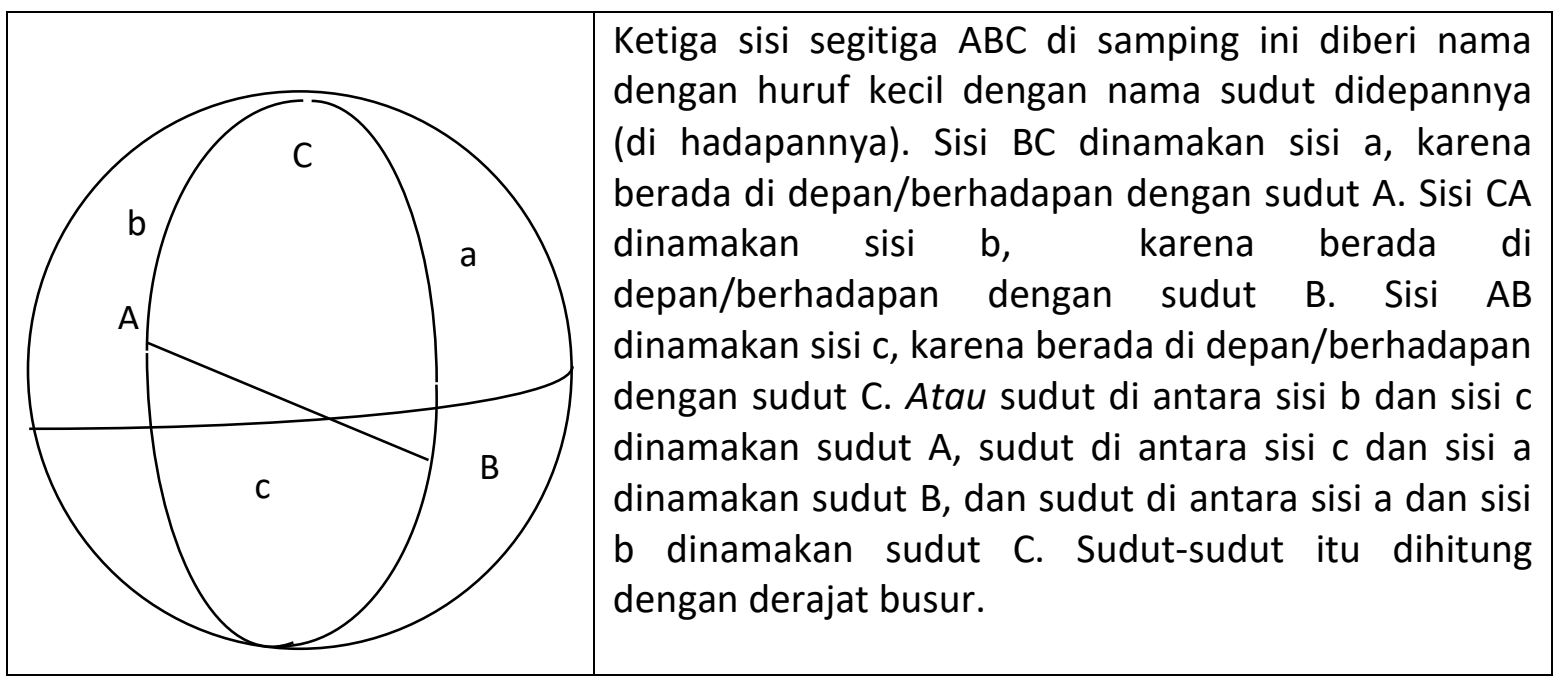

Gambar 1. Segitiga Bola ABC

\section{Awal Waktu Shalat}

Demikian halnya menghitrung awal waktu shalat, karena setiap shalat ditentukan waktunya masing-masing, dilakukan dengan menggunakan "ilmu ukur segitiga bola (spherical trigonometri)".

Menentukan waktu-waktu shalat, sebagaimana disebutkan dalam surat 4/al-Nisâ' ayat 103, dikemukakan bahwa shalat fardhu itu ditentukan waktunya. ${ }^{1}$ Sedangkan waktu shalat itu dijelaskan dalam surat 17/al-Isrâ' ayat 78 dan surat 11/Hud ayat $114 .^{2}$ Pada surat yang pertama, Allah SWT memerintahkan agar shalat didirikan sejak Matahari tergelincir (dulûk al-syams) sampai gelap malam (gasâq al-lail), dan waktu Shubuh (qur'ân al-fajr). Pada surat yang kedua disebutkan agar shalat didirikan pada tepi siang, pagi dan petang (tarafay al-nahâr) dan pada bagian permulaan malam (zulafan min al-lail). Dari kedua

${ }^{1}$ Lihat Q.S. 4/al-Nisâ ayat 103 berikut:

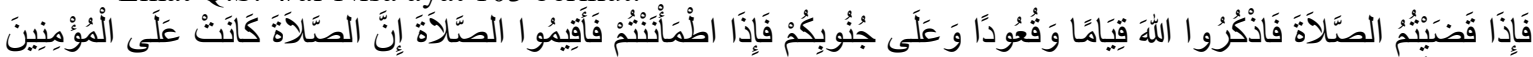

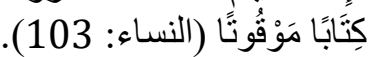

"Maka apabila kamu telah menyelesaikan shalat (mu), ingatlah Allah di waktu berdiri, di waktu duduk dan di waktu berbaring. Kemudian apabila kamu telah merasa aman, maka dirikanlah shalat itu (sebagaimana biasa). Sesungguhnya shalat itu adalah kewajiban yang ditentukan waktunya atas orangorang yang beriman”.

${ }^{2}$ Q.S. 17/al-Isra adalah 17, adalah:

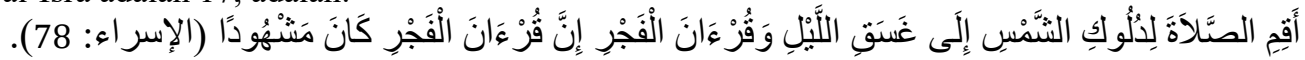

"Dirikanlah shalat dari sesudah matahari tergelincir sampai gelap malam dan (dirikanlah pula shalat) shubuh. Sesungguhnya shalat shubuh itu disaksikan (oleh malaikat)”.

Sedangkan Q.S. 11/Hûd ayat 114:

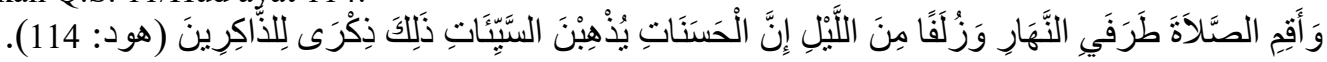

"Dan dirikanlah shalat itu pada kedua tepi siang (pagi dan petang) dan pada bahagian permulaan daripada malam. Sesungguhnya perbuatan-perbuatan yang baik itu menghapuskan (dosa) perbuatanperbuatan yang buruk. Itulah peringatan bagi orang-orang yang ingat”. 
ayat di atas, Rasulullah SAW seperti dijelaskan dalam sebuah hadis yang diriwayatkan Muslim dari 'Abdullâh bin 'Umar memberikan penjelasan bahwa shalat wajib dilakukan sebanyak lima kali dalam sehari semalam dengan batas-batas waktu tertentu. ${ }^{3}$ Pengunaan ilmu falak sangat membantu dan dapat menjadi pedoman praktis, karena pada umumnya kaum muslimin sekarang tidak lagi melihat perjalanan Matahari dalam menentukan kapan dimulai shalat, tetapi hampir secara keseluruhan praktik kaum muslimin melihat pada jam waktu dalam hal memulai pelaksanaan shalat, atau dalam mengumandangkan adzan sebagai tanda memulai waktu shalat tersebut. Muhammadiyah merupakan sebuah organisasi yang modernis, namun tidak semua warganya memiliki pandangan dan faham akan modernisasi, apalagi pada level akar rumput, yaitu tingkat daerah, cabang dan ranting-rantingnya. Di samping pemahaman terhadap astronomi Islam atau ilmu falak yang menjadi induk metode perhitungan arah qiblat dan waktu-waktu shalat merupakan ilmu yang langka dikuasai oleh setiap orang. Esensi dan kebutuhan akan pengetahuan tersebut sangat besar, terutama untuk dapat melaksanakan ibadah sesuai dengan tuntunan ajaran agama (Islam), yakni memenuhi syarat-syarat dalam pelaksanaan ibadah, sehingga setiap warga Muhammadiyah dapat melaksanakan ibadah dengan baik dan benar.

Demikian halnya realitas yang terjadi pada warga Muhammadiyah, khususnya di daerah Kabupaten Batang Propinsi Jawa Tengah yang menjadi sasaran program pengabdian masyarakat ini. Sebahagian besar warga Muhammadiyah se-daerah Kabupaten Batang belum memahami dengan benar tatacara perhitungan arah qiblat dan waktu-waktu shalat, serta bagaimana praktik pengukuran arah qiblat tersebut. Bahkan, para pengurusnyapun hanya sebatas pemahaman keagamaan, di mana sebelum melakukan shalat itu harus terpenuhi syarat-syaratnya terlebih dahulu, di antaranya harus menghadap qiblat dan sudah memasuki waktu. Namun, bagaimana cara perhitungannya sebahagian besar juga tidak mengetahuinya.

\footnotetext{
${ }^{3}$ Hadis tersebut berbunyi:

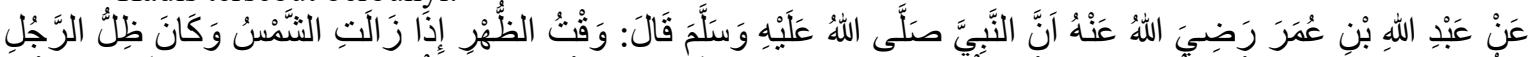

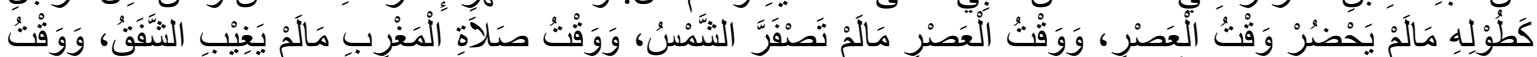

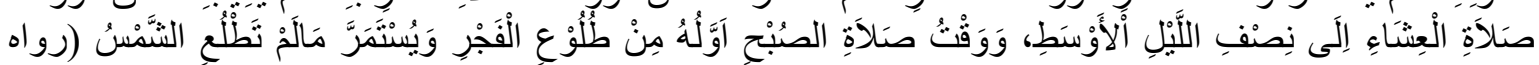

"Dari 'Abdillah bin 'Umar Ra., bahwasanya Nabi SAW bersabda: Waktu Zhuhur ialah bila Matahari sudah tergelincir (ke arah Barat), hingga bayang-bayang orang sama dengan panjangnya selama belum masuk waktu 'Ashar. Akhir waktu 'Ashar itu selama belum menguningnya Matahari, dan waktu shalat Maghrib hingga sebelum hilangnya awan (mega) merah, dn waktu shalat 'Isya ialah hingga tengah malam. Sedangkan waktu shalat shubuh itu mulai terbit fajar hingga sebelum terbit matahari" (H.R. Muslim). Lihat al-Sayyid al-Imâm Muhammad bin Isma'îl al-Kahlâny, Subul al-Salâm, Juz I, hal. 106. 
Sebelum proposal ini dibuat dan diajukan, telah dilakukan terlebih dahulu sebuah studi pendahuluan berupa penelitian lapangan (yang masih dalam proses), di mana diperoleh data awal bahwa warga Muhammadiyah Kabupaten Batang, termasuk para guru sekolah Muhammadiyah serta para pengurusnya yang jumlahnya mencapai 300 orang lebih, secara acak dengan mengambil sampel 50 orang, hanya 3 (tiga) orang (6\%) yang sedikit memahami cara menghitung arah qiblat dan waktu-waktu shalat tersebut. Itupun terbatas pada pemahaman dan hanya guru mata pelajaran eksakta, yang mengajar mata pelajaran matematika dan geografi. ${ }^{4}$ Data awal ini akan diulang keabsahannya setelah selesai pelaksanaan penelitian, sesuai jadwal yang telah direncanakan.

Kegiatan perlatihan perhitungan arah qiblat dan awal waktu shalat ini sangat berperan besar bagi warga Muhammadiyah (khususnya di daerah Kabupaten Batang), karena telah menjadi komitmen persayarikatan, bahwa setiap warganya tidak boleh bersikap taqlid (mengikuti suatu pandangan/faham tanpa memahami dalil atau argumentasinya). Setiap warga Muhammadiyah, sekurang-kurangnya (paling minim) adalah bersikap ittiba' (mengikuti suatu pandangan/faham dengan memahami dalil atau alasannya. Bahkan, diharapkan mampu melakukan tarjih (melakukan upaya dengan berfikir lebih luas, memilah dan memilih yang terbenar, terbaik dan terkuat), serta berijtihad (melakukan kajian secara mendalam, diiringi analisa yang tajam, serta kemampuan memproduksi suatu hukum).

Dengan pelatihan perhitungan arah qiblat dan waktu-waktu shalat ini diharapkan agar para peserta yang mengikutinya sekurang-kurangnya mampu memahami dasar pemikiran pentingnya melakukan perhitungan yang menjadi syarat sahnya ibadah shalat tersebut (selevel dengan ittiba'), bahkan diharapkan akan menjadi warga yang mampu menentukan sendiri cara menghadap qiblat dengan benar dan melakukan shalat sesuai dengan tuntunan ajaran Islam, yakni dalam waktu-waktu yang telah ditetapkan (selevel dengan melakukan tarjih maupun ijtihad).

Selain itu, pelaksanaan pengabdiaan masyarakat di Kabupaten Batang Propinsi Jawa Tengah ini juga menjadi ajang promosi, karena ternyata minat masyarakatnya cukup besar dan signifikan untuk menjadi mahasiswa UHAMKA. 


\section{MASALAH}

Menguasai perhitungan arah qiblat dan waktu-waktu shalat (awal waktunya) sangatlah penting bagi umat Islam, termasuk warga Muhammadiyah yang notabene semuanya pemeluk agama Islam agar mereka dapat memenuhi syarat-syarat dan melaksanakan shalat tersebut dengan benar.

Sementara itu, sebagaimana dikemukakan di muka melalui perolehan data awal bahwa permasalahan mitra sangat minim dalam memiliki kemampuan perhitungan arah qiblat dan waktu-waktu shalat, serta teknik pengukurannya, yakni hanya $6 \%$ (3 orang dari 50 orang/responden yang dijadikan sampel).

Selanjutnya, dapat diidentifikasi permasalahan untuk memiliki kemampuan perhitungan dengan benar harus memenuhi persyaratan, sebagai berikut:

- Memiliki kemampuan dan semangat yang tinggi untuk belajar;

- Memiliki sikap disiplin dan tidak mudah bosan (pantang putus asa);

- Memiliki pemahaman dasar agama tentang persyaratan melakukan ibadah shalat;

- Memiliki landasan ilmu hitung (dasar-dasar matematika) dengan baik;

- Memiliki dasar-dasar ilmu geografi (mengetahui letak geografis suatu tempat di permukaan bumi) dengan baik;

- Memiliki dasar-dasar pengetahuan ilmu falak/astronomi;

- Memliki dan mampu menggunaklan kalkulator scientific;

- Memiliki sarana/alat untuk mengukur arah qiblat, seperti: kompas, penggaris panjang, segitiga siku dan busur derajat;

- Mampu menggunakan/mengaplikasikan software winhisab; dan

- Mampu menghitung dan mengukur bayang-bayang matahari dalam menentukan arah qiblat setiap kali terjadi.

Dari identifikasi yang dikemukakan di atas, pada umumnya (sebagian besar) para peserta (sasaran latih) hanya memiliki kemampuan dan semangat yang tinggi untuk belajar dan kemungkinan memiliki sikap disiplin. Sebagian besar belum memiliki kriteria yang terindentifikasi tersebut.

Oleh karena itu, bersama para mitra (Pimpinan Daerah Muhammadiyah Kabupaten Batang Propinsi Jawa Tengah) para peserta latihan mampu menghitung arah qiblat dan waktu-waktu shalat, serta mengukur arah qiblat dengan baik dan benar. 


\section{Pelatihan ini ditujukan:}

Terbentuknya kader-kader Muhammadiyah yang memahami dan mahir perhitungan falakiyah, khususnya perhitungan waktu-waktu ibadah (arah qiblat dan waktu-waktu shalat); Sedangkan manfaat yang diperoleh dari pelatihan ini terjalinnya kerjasama dengan para mitra kerja, yang dapat ditindaklanjuti dengan kegiatan lainnya di masa mendatang.

\section{METODE PELAKSANAAN}

Untuk tercapainya maksud dan tujuan, serta target kegiatan pengabdian masyarakat berupa pelatihan tercapai dengan baik, diperlukan metode pendekatan sebagai berikut:

- Memberikan motivasi agar para peserta memperkuat kemauan dan semangat belajar yang tinggi, serta sikap yang sungguh-sungguh dan disiplin yang tinggi;

- Memberikan wawasan umum dan dasar-dasar ilmu falak tentang letak geografis suatu tempat di permukaan bumi;

Memberikan ilmu perhitungan arah qiblat dan waktu-waktu shalat, serta praktik pengukuran arah qiblat.

\section{PEMBAHASAN}

Sesuai dengan program pengabdian dan pemberdayaan kepada masyarakat yang telah direncanakan, maka target luaran yang dapat dicapai berupa produk dan jasa, yakni:

- Produk: Terbentuknya kader-kader ilmu falak, yang mampu menghitung arah qiblat dan waktu-waktu shalat.

- Jasa: Tersosialisasinya ilmu falak sebagai bagian ilmu keagamaan yang berperan penting dalam menentukan waktu-waktu ibadah bagi umat Islam, sekaligus memperkenalkan UHAMKA kepada masyarakat luas.

Evaluasi produk dan jasa tersebut dilakukan melalui pelatihan perhitungan arah qiblat dan waktu-waktu shalat, sekurangnya tercapai $60-70 \%$ para peserta latihan mampu menguasainya.

Kriteria proses kegiatan, bagi yang mampu melakukan perhitungan arah qiblat, para peserta latihan benar-benar menguasai cara-cara perhitungannya, yakni tahu benar rumus segitiga bola (spherical trigonometri) dan pengunnan calculator scientific sebagai sarana/alat hitungnya. Di samping, mereka juga mampu melakukan pengukuran arah qiblat 
dengan benar, dengan mengaplikasikan penggunaan kompas dan sarana lain yang mendukung peengukuran arah qiblat tersebut.

Sedangkan mampu menghitung awal waktu shalat yang terdiri dari shalat zhuhur, ashar, maghrib, 'isya, shubuh, waktu syuruq (terbit matahari) dan waktu shalat $\underline{\text { dhuha. }}$ Perhitungan awal waktu shalat tersebut hanya dapat diwujudkan dengan mengaplikasikan penggunaan salah satu software, dalam hal ini software winhisab.

Selanjutnya, mereka (para peserta latihan) akan diuji kelayakannya oleh para Pelatih (Tim pelaksana yang memiliki kualifikasi ilmu falak/astronomi). Selain itu, bagi peserta yang lolos uji dan dinyatakan lulus akan memperoleh sertifikat sebagai bukti pernah mengikuti pelatihan dengan baik dan telah lolos uji dengan standar nilai tertentu, yaitu sangat baik (A, dengan score nilai antara 85 - 100), baik (B, dengan score nilai antara 70 84), dan cukup (C, dengan score nilai antara $56-69)$.

\section{KESIMPULAN}

Program Pengabdian dan Pemberdayaan kepada Masyarakat Kabupaten Batang Jawa Tengah selama 3 (tiga) bulan (April - Juni 2017) berupa pelatihan perhitungan arah qiblat dan waktu-waktu shalat dengan dua target luaran yang akan dihasilkan, yakni:

- Sekurang-kurangnya $70 \%$ (35 orang dari 50 orang) peserta pelatihan mampu melakukan perhitungan arah qiblat dan mempraktikkan pengukurannya;

- Sekurang-kurangnya 60\% (30 orang dari 50 orang) peserta pelatihan mampu menghitung awal waktu shalat dengan mempraktikkan software winhisab yang menjadi standar Kementerian Agama Republik Indonesia..

\section{UCAPAN TERIMA KASIH}

Ucapan terima kasih kepada LPPM UHAMKA sebagai penyandang dana kegiatan ini. Terimakasih juga kepada Warga Muhammadiyah khususnya di daerah Kabupaten Batang Propinsi Jawa Tengah yang menjadi sasaran program pengabdian masyarakat ini. Serta para mitra (Pimpinan Daerah Muhammadiyah Kabupaten Batang Propinsi Jawa Tengah).

\section{DAFTAR PUSTAKA}

Arifin, Jaenal, (2004), Pemikiran Hisab Rukyah KH. Nor Ahmad SS di Indonesia, Semarang : Tesis Program Pascasarjana IAIN Walisongo Semarang.

Arikunto, Suharsimi, (2002), Prosedur Penelitian Suatu Pendekatan Praktek, Jakarta: Penerbit Rineka Cipta. 
Arkanuddin, Mutoha dan Fahrurrazi, Djawahir, (2009), Ilmu Falak dan Pergerakan Benda Langit,Yogyakarta: RHI.

Hambali, Slamet, (2011), Ilmu Falak, Penentuan Awal Waktu Salat dan Arah Kiblat Seluruh Dunia, cet. I, Semarang : Program Pascasarjana IAIN Walisongo.

Khafid, (2012), Modul Kuliah Astronomi dan Hisab Kontemporer, Semarang: Pascasarjana IAIN Walisongo.

Supriatna, Encup, (2007), Hisab Rukyat dan Aplikasinya, Bandung: PT Refika Aditama. 